\title{
Estimating Paddy Rice Biomass Using Radarsat-2 Data Based on Artificial Neural Network
}

\author{
JING Zhuo-xin \\ Key Laboratory of Geographical Information Science, \\ Ministry of Education, East China Normal University, Joint \\ Laboratory for Environmental Remote Sensing and Data \\ Assimilation, ECNU \& CEODE \\ Shanghai, China \\ jjjzxhi@126.com \\ WANG Ke-jing \\ Key Laboratory of Geographical Information Science, \\ Ministry of Education, East China Normal University, Joint \\ Laboratory for Environmental Remote Sensing and Data \\ Assimilation, ECNU \& CEODE
}

\begin{abstract}
Accurate estimation of rice biomass plays a role in crop growth monitoring and agricultural carbon cycle. Dualpolarization Radarsat-2 data were used in this study for rice biomass inversion. Artificial neural network (ANN) method has been applied to simulate the relation between rice canopy parameters (height, moisture content and biomass etc.) and radar backscattering coefficients. By comparing the network training performance and RMSE of different polarization combinations, HV data had better accuracy which was selected as input of the network for biomass inversion. The distribution of rice biomass was also mapped at regional scale. This study indicated that Radarsat-2 SAR data could be used to estimate rice biomass with the root mean square error (RMSE) of $<108$ $\mathrm{g} / \mathrm{m}^{2}$.
\end{abstract}

Index Terms-Biomass; BP neural network; Radarsat-2 data; HH, HV polarization.

\section{INTRODUCTION}

Most paddy rice is planted in warm and humid regions in the world, frequent cloud cover or rainfall often occurs in rice growing season. Owing to the acquisition limitations of optical remote sensing data, it is very difficult to carry out real-time monitoring of crop growth. Synthetic Aperture Radar (SAR), with "all-weather" and day or night imaging capabilities, can provide effective data when optical remote sensing data is unavailable. Moreover, SAR can record information on the geometric structure and dielectric properties of vegetation ${ }^{[1-4]}$. Radar remote sensing imagery has been proven to be one appropriate data source for agricultural monitoring.

Accurate estimation of rice biomass has significance in rice yield estimation. Recent research on monitoring rice growth have demonstrated that Radar backscattering coefficients have great relevance to the rice biophysical parameters, such as biomass ${ }^{[5]}$; Shao et al. (2001) used Radarsat-1 HH polarization data to monitor rice crops and retrieve rice growth parameters $^{[6]}$; Wu et al. (2011) investigated the correlation between the rice growth parameters acquired in fieldwork and

\author{
Shanghai, China \\ wkj_3210@163.com
}

ZHANG Yuan*

Key Laboratory of Geographical Information Science, Ministry of Education, East China Normal University, Joint Laboratory for Environmental Remote Sensing and Data Assimilation, ECNU \& CEODE Shanghai, China yzhang@geo.ecnu.edu.cn

the backscattering coefficients derived from SAR data ${ }^{[7]}$. The vertical structure of rice plant represents strong extinction to the radar beam at different polarization mode. Both $\mathrm{HH}$ and HV polarization radar scattering coefficients have strong correlation with vegetation structure variables (e.g. leaf area index and biomass) ${ }^{[8]}$.

In this study, Radarsat-2 dual-polarization data were acquired to observe rice paddies. Artificial neural network method (ANN) was applied to simulate the relation between rice parameters and radar backscattering coefficients. Different polarization combinations of Rradarsat-2 data were investigated as input of training network by combining with the measured rice parameters. The most appropriate polarization data will be selected for rice biomass inversion.

\section{STUDY AREA AND DATA}

This study was conducted in Dengta of Liaoning province in the northeast of China. The eastern part of Dengta is high hills and the Changbai Mountains, which accounts for about one-third of the total area of this city. And the remaining twothirds are the flood plains with fertile soil. The two major rivers (the Hunhe River and Taizihe River) provide the rich irrigation water for the region. Adequate amount of water and fertile soil make the region a major farming area in the Liaohe watershed. A large part of this area is used as agricultural fields, mainly the rice paddies, which contributes to obtain accurate rice spatial distribution information (Fig. 1).

The Radarsat-2, Canada's high-resolution commercial radar satellite, was launched on Dec. 14, 2007. The SAR sensor onboard this satellite is able of acquiring C-band data at a resolution of $3 \mathrm{~m}$ at $10^{\circ}-60^{\circ}$ incidence angle. Fine mode products $\mathrm{SGX}$ in $\mathrm{HH} / \mathrm{HV}$ polarization with pixel space of $3.125 \mathrm{~m} \times 3.125 \mathrm{~m}$ were acquired, and then were resampled into a $15 \mathrm{~m} \times 15 \mathrm{~m}$ resolution image data by the nearest neighbor method. And the Radarsat-2 HV data in July 28, Aug. 14 and in Sept. 14 were applied to produce the pseudo-color composition map for rice classification. The SAR data acquired 
on Sept. 14, 2011 (rice maturing stage) were used in this study for rice biomass inversion (Fig. 1).

The ground measurements in rice field were carried out in synchronical with the Radarsat- 2 observation. Total of 25 sites were selected in Sept. 14, 2011. Field measurements at each site were positioned by GPS instrument. The observed rice parameters mainly involved rice height, canopy moisture content and above-ground biomass by averaging triple measurements at sampled sites. Moisture content of rice is determined by dividing the difference between the fresh weight and dry weight of sample rice plants by the fresh weight, it was expressed as a percentage $(\%)$. $123^{\circ} 0^{\circ} 0^{\prime \prime} \mathrm{E}$ $123^{\circ} 20^{\circ} 0^{\prime \prime} \mathrm{E}$

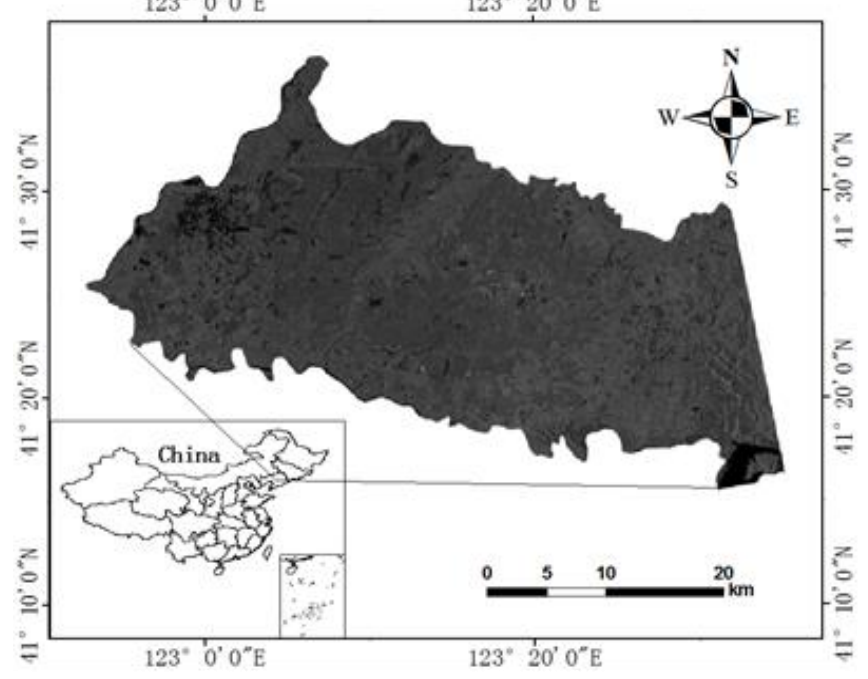
2011

Fig.1 Study area covered by Radarsat- 2 image that acquired on Sept. 14,

\section{METHOD}

The Radarsat-2 data processing was divided into four parts: geometric correction and co-registration, speckle noise reduction, radiometric calibration and rice classification. They were processed by the ESA radar image processing professional software NEST-4.1 C (www.array.ca/nest). With the satellite orbit parameters in image header files, the SAR image obtained high position accuracy after geometric correction. To extract the rice paddy, it is necessary to reduce the inherent speckle noise in raw image. A Gamma MAP filter with $11 \times 11$ window was used for speckle-filtering raw radar imagery prior to classification. Then, the backscatter coefficients $\left(\sigma^{0}\right)$ were calculated by the calibration equation:

$$
\sigma^{0}=10 * \lg \left[\frac{\left(D N_{j k}^{2}+A_{0}\right)}{A_{j}}\right]+10 * \lg \left(\sin I_{j}\right)
$$

Where, DN is the digital number of Radatsat-2 image, $\mathrm{A}_{0}$, $A_{j}$ is the automatic gain control factor, and $I_{j}$ is the local incidence angle of each pixel across the range direction.

Large rice fields in this study area make the rice identification easy, thus visual interpretation was applied to extract rice class from the composition map. Then, backscattering coefficients of rice field were obtained by masking the Radatsat- 2 image with the classified rice map, the backscattering coefficient map was used as input of the neural network model for rice biomass retrieval.
A neural network method was developed to estimate the rice biomass from Radarsat- 2 data ${ }^{[12]}$. The most commonly used neural network is back-propagation (BP) type. The BP neural network consists of one input layer, one output layer, and one or more hidden layers. In this study, the input vector contains the backscattering coefficients of rice, and the output vector contains the rice height, moisture content and biomass measured in rice field. Recent studies have shown that the backscattering coefficient is sensitive to crop biomass and dielectric property ${ }^{[8-11]}$. In general, the rice biomass is positively related to canopy height, and training sample set is produced based on the positive correlation between the two. The increase in water content make the dielectric property linearly increase, which relates to the rice backscatter coefficients. Therefore, rice height, biomass and moisture content were considered into the training and inversion as an important factor.

The training process is carried out with the training sample set for defining one optimum network. When the inversion is performed, the input to the network is a set of rice backscattering coefficients at different polarization $(\mathrm{HV}, \mathrm{HH}$ and $\mathrm{HH}+\mathrm{HV}$ ). So three training process were carried out, and root mean square error (RMSE) between the observed and simulated values were calculated for assessing the inversion accuracy.

\section{RESULT AND DISCUSSION}

After multiple training and testing, the optimal neural network was finally obtained. Considering the accuracy and computation time, one hidden layer with 20 nodes was found to better train the network. The training processes were performed at Matlab environment and three network at different polarization $(\mathrm{HH}, \mathrm{HV}, \mathrm{HH}+\mathrm{HV})$ were saved. $\mathrm{P}$ represents the network training performance and RMSE is the error between network output and target output, which were listed in Table 1, the performance is better when the $\mathrm{P}$ closer to 0 . The $\mathrm{HV}$ data with RMSE of $107.82 \mathrm{~g} / \mathrm{m}^{2}$ was evidently superior to the $\mathrm{HH}$ data with RMSE of $217.39 \mathrm{~g} / \mathrm{m}^{2}$. This could be due to the vertical structure of rice plant. For C-band, canopy volume scattering dominates in the backward scattering. The crosspolarization data is directly related to volume scattering of rice canopy while the co-polarization one is related to doublebounce and scattering from ground of rice plants, so HV data was more highly correlated to rice structure parameters than $\mathrm{HH}$ data ${ }^{[10]}$. Wu et al. (2011) had demonstrated that $\mathrm{HV}$ or $\mathrm{VH}$ was more suitable than the $\mathrm{HH}$ and $\mathrm{VV}$ data for retrieving rice parameters, such as rice biomass or height. Thus in this present study, the HV data was selected as the input image for the retrieval of rice parameters.

The inputs are the rice HV backscattering coefficients, the outputs are the rice parameters (rice height, moisture content, biomass). In this study, rice biomass in Sept. 14 need to be retrieved, so biomass was chosen as only retrieved value. From the scatterplot of the retrieved against measured biomass, it generally showed strong consistency in inversion result at most sampled sites (Fig. 3). However, an obvious outlier was observed, the measured rice biomass at this sites $\left(2006.4 \mathrm{~g} / \mathrm{m}^{2}\right)$ 
was estimated with a large error of $422.88 \mathrm{~g} / \mathrm{m}^{2}$. The errors in field observation could contribute to the poor result. Totally, rice parameters were retrieved with acceptable error (RMSE of $107.82 \mathrm{~g} / \mathrm{m}^{2}$ ). Therefore, the result showed the rice biomass was estimated with acceptable accuracy. Meanwhile, the rice biomass spatial distribution within the study area was mapped (Fig.4). Estimated results showed that the rice biomass ranged from $1400 \mathrm{~g} / \mathrm{m}^{2}$ to $2800 \mathrm{~g} / \mathrm{m}^{2}$, which is basically in accordance with the data measured in the rice field.

TABLE I. COMPARING THE BP NETWORK PERFORMANCE AND RMSE AT DIFFERENT POLARIZATION

\begin{tabular}{|c|c|c|}
\hline $\begin{array}{c}\text { Different } \\
\text { polarization }\end{array}$ & p & RMSE \\
\hline $\mathrm{HV}$ & 0.00218 & $107.82 \mathrm{~g} / \mathrm{m}^{2}$ \\
\hline $\mathrm{HH}$ & 0.0169 & $217.39 \mathrm{~g} / \mathrm{m}^{2}$ \\
\hline $\mathrm{HV}+\mathrm{HH}$ & 0.00222 & $148.70 \mathrm{~g} / \mathrm{m}^{2}$ \\
\hline
\end{tabular}

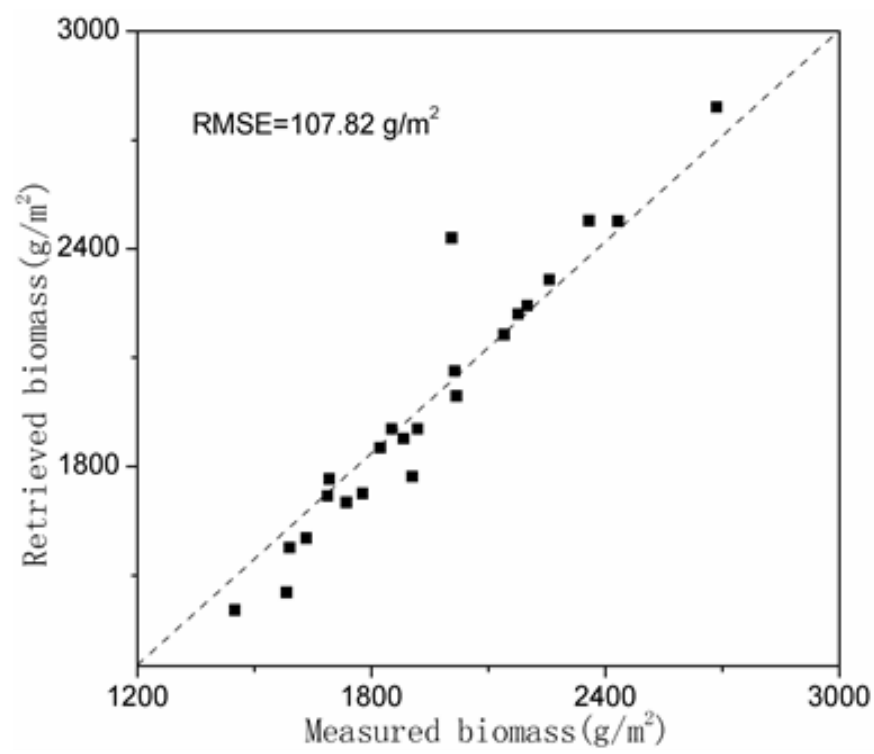

Fig.2 Comparison of the retrieved and measured results

By comparing with the measured data, the inversion results can explain the availability of neural network model. The error could be attributed to some reasons below: (1) the errors in field observation; (2) speckle noise in SAR image cannot be completely eliminated by existing filtering algorithm, which inevitably affects the quality of the radar data and further inversion accuracy; and (3) The limited rice measurements ( 25 sites) have a great influence on obtaining the optimal network. Future work will be conducted by introducing the rice canopy scattering model to increase the training samples, which could be helpful for establishing the optimal network and improving the inversion accuracy.

\section{CONCLUSION}

Radarsat-2 data has been applied to retrieve rice biomass based on the ANN method at spatial scale. This study demonstrates the potential of dual-polarization Radarsat-2 SAR imagery to estimation of rice biomass with better accuracy (RMSE of $107.82 \mathrm{~g} / \mathrm{m}^{2}$ ). For C-band Radarsat-2, HV polarization data was more suitable for retrieving rice biomass than the $\mathrm{HH}$ data. Furthermore, the feasibility of neural network method was tested as an effective approach to estimate rice biomass, which could be effectively applied to quantitative retrieval research in remote sensing applications.

\section{ACKNOWLEDGMENTS}

This work was supported by research grants from the National Natural Science Foundation of China (No. 41001202) and National Basic Research Program of China (973) (No. 2010CB951603).

\section{REFERENCES}

1. C. Yonezawa, M. Negishi, K. Azuma, M. Watanabe, N. Ishitsuka, S. Ogawa, and G. Saito, "Growth monitoring and classification of rice fields using multitemporal RADARSAT-2 fullpolarimetric data," International Journal of Remote Sensing, 2012, vol. 33, pp. 5696-5711.

2. F. Ribbes and T. Le Toan, "Rice field mapping and monitoring with RADARSAT data," International Journal of Remote Sensing, 1999, vol. 20, pp. 745-765.

3. I. Choudhury and M. Chakraborty, "SAR signature investigation of rice crop using RADARSAT data," International Journal of Remote Sensing, 2006, vol. 27, pp. 519-534.

4. M. Chakraborty, K. R. Manjunath, S. Panigrahy, N. Kundu, and J. S. Parihar, "Rice crop parameter retrieval using multi-temporal, multi-incidence angle Radarsat SAR data," ISPRS Journal of Photogrammetry and Remote Sensing, 2005, vol. 59, pp. 310-322.

5. T. Kurosu , M. Fujita and C. Kazuo , "Monitoring of rice crop growth from space using the ERS-1 C-band SAR". IEEE Transactions on Geoscience and Remote Sensing, 1995, vol.33, pp. 1092-1096.

6. J. J. Liao, Y. Shao, H. D. Guo, and X. T. Fan, "A comparison of observation with theory [rice biomass]," Geoscience and Remote Sensing Symposium, 2000. Proceedings. IGARSS 2000. IEEE 2000 International, 2000, vol.5, pp. 1933-1935.

7. F. Wu, C. Wang, H. Zhang, B. Zhang, and Y. X. Tang, "Rice crop monitoring in south China with RADARSAT-2 quadpolarization SAR data," Geoscience and Remote Sensing Letters, IEEE, 2011, vol. 8, pp. 196-200.

8. A. Bouvet, T. Le Toan and L. Nguyen, "Monitoring of the rice cropping system in the Mekong Delta using ENVISAT/ASAR dual polarization data," IEEE Transactions on Geoscience and Remote Sensing, 2009, vol. 47, pp. 517-526.

9. S. B. Yang, X. Y. Zhao, B. B. Li, and Q. H. Guo, "Interpreting RADARSAT-2 Quad-Polarization SAR Signatures From Rice Paddy Based on Experiments," IEEE Geoscience and Remote Sensing Letters, 2012, vol. 9, pp. 65-69.

10. S. Gao, Z. Niu, N. Huang, and X. H. Hou, "Estimating the Leaf Area Index, height and biomass of maize using HJ-1 and RADARSAT-2," International Journal of Applied Earth Observation and Geoinformation, 2013, vol. 24, pp. 1-8.

11. Y. Zhang, Z. H. Zhang, S. L. Su, and J. P. Wu. Remote sensing estimation of paddy rice biomass based on microwave canopy scattering model. Transactions of the Chinese Society of Agricultural Engineering, 2011, vol.27, pp. 100-105.

12. N. Baghdadi, S. Gaultier and C. King, "Retrieving surface roughness and soil moisture from synthetic aperture radar (SAR) data 


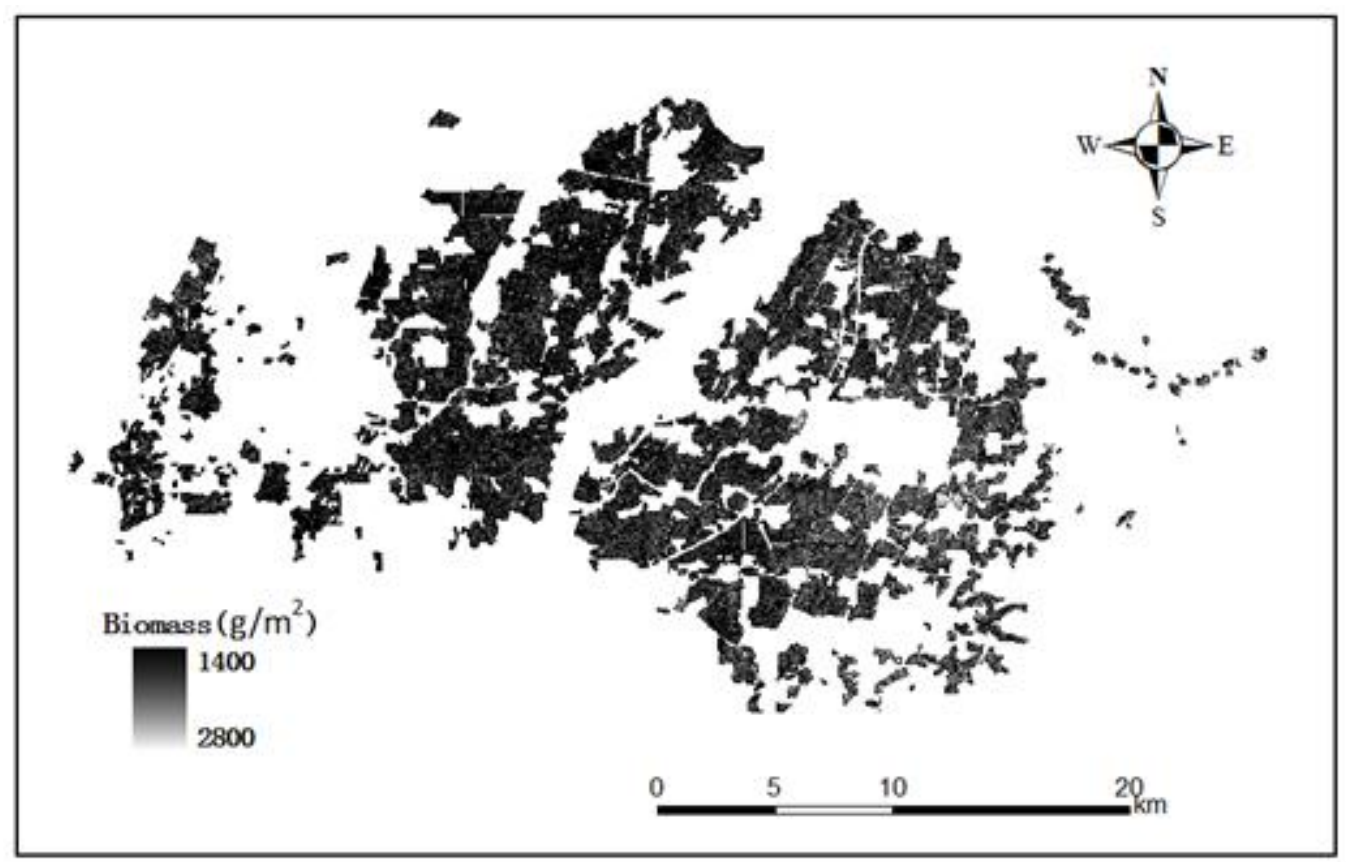

Fig.3 Spatial distribution map of retrieved rice biomass. 